\title{
A produção de blocos de concreto confeccionados com rejeitos da construção civil para execução em alvenaria de vedação: a busca por alternativas sustentáveis.
}

\section{The production of concrete blocks made with tailings from the civil construction for execution in masonry of fence: the search for sustainable alternatives.}

\author{
Tiago Luiz da Costa ${ }^{1}$ \\ Mateus Bravo de Aguiar ${ }^{2}$ \\ Wesley Luiz Mendes Moraes ${ }^{3}$ \\ Erico Tiago Dias ${ }^{4}$ \\ Diego Silva ${ }^{5}$ \\ Antônio Pires Azevedo Júnior ${ }^{6}$
}

\begin{abstract}
Resumo
Esta pesquisa consiste na produção de blocos de concreto com rejeitos provenientes da construção civil para alvenaria de vedação. A pesquisa é justificada devido aos problemas enfrentados na construção civil, tendo como foco o desperdício de materiais de pequenas e grandes construções e seu, consequente, dano ao meio ambiente. O objetivo da pesquisa é a confecção de blocos de concreto para alvenaria de vedação, utilizando rejeitos da construção civil, que atendam as normas técnicas brasileiras vigentes, quanto à resistência a compressão, empregando o mesmo na construção civil como material reciclado, uma vez que o bloco de vedação não exige alta resistência mecânica, podendo contribuir como uma solução mais econômica. O entulho foi separado, triturado e peneirado para que se obtivesse a granulometria desejável, posteriormente adicionado ao cimento, areia e pó de pedra, moldados conforme preceitos das normas técnicas da ABNT - Associação Brasileira de Normas Técnicas. Estudou-se a resistência à compressão, dos blocos após a cura, comparando com a resistência dos blocos convencionais.
\end{abstract}

Palavras-chave: Blocos. Materiais de Construção. Entulho. Construção Civil.

\begin{abstract}
This research consists of the production of concrete blocks with rejects from civil construction for seal masonry. The research is justified due to the problems faced in the construction, focusing on the waste of materials of small and large buildings and its, consequently, damage to the environment. The objective of the research is the preparation of concrete blocks for masonry of sealing, using civil construction rejects, that meet the Brazilian technical norms in force, as to the resistance to compression, employing the same in civil construction as Recycled material, since the sealing block does not require high mechanical resistance and can contribute as a more economical solution. The rubble was separated, shredded and sifted to obtain the desirable particle size, subsequently added to the cement, sand and stone dust, shaped according to the precepts of the technical norms of ABNT-Brazilian Association of technical Standards. It was studied the resistance to compression, of the blocks after the cure, compared with the resistance of the conventional blocks.
\end{abstract}

Keywords: Blocks. Building materials. Rubble. Civil Construction.

Artigo recebido em 10 de Outubro de 2017 e aprovado em 21 de Março de 2018.

${ }^{1}$ Discente do curso de Engenharia Civil - PUC Minas/Barreiro. E-mail: tiagozeppelin@outlook.com

${ }^{2}$ Engenheiro Civil - PUC Minas/Barreiro. E-mail: mateus.aguiar@sga.pucminas.br

${ }^{3}$ Discente do curso de Engenharia Civil - PUC Minas/Barreiro. E-mail: wesleyluiz1995@ outlook.com

${ }^{4}$ Discente do curso de Engenharia Civil - PUC Minas/Barreiro. E-mail: ericotiago@ gmail.com

${ }^{5}$ Discente do curso de Engenharia Civil - PUC Minas/Barreiro. E-mail: dieggo.177@ @otmail.com

${ }^{6}$ Mestre em Engenharia de Estruturas - UFMG. E-mail: azevedojr@yahoo.com.br 


\section{Introdução}

O setor de Construção Civil sempre esteve ligado a questões relacionadas a perdas e desperdícios, gerando um grande volume de resíduos. O gerenciamento destes resíduos nos grandes centros urbanos está se tornando cada dia mais difícil, devido à falta de locais específicos para despejo desses resíduos, fazendo com que o custo da remoção fique cada vez maior.

Esse fato vem contribuir para o depósito clandestino dos resíduos, seja em terrenos baldios, ao longo das margens dos rios, como nas ruas periféricas etc. Suas consequências geram a degradação da qualidade de vida urbana em aspectos como transportes, enchentes, poluição visual, proliferação de vetores de doenças, entre outros.

Diante deste cenário, várias cidades brasileiras vêm adotando medidas para o descarte desses resíduos visando a eliminação de pontos clandestinos de descarte e a possibilidade de sua utilização como materiais de construção alternativos a custos mais baixos.

A resolução $n^{\circ}$ 307/02 do Conselho Nacional do Meio Ambiente (2002), classifica os resíduos descartados da construção civil, bem como seus possíveis destinos, em 4 classes:

Classe A: Podem ser reutilizados na própria obra como agregados, como: materiais cerâmicos, tijolos, argamassa, etc. Se não forem reaproveitados, estes resíduos podem ser encaminhados para usinas ou aterros destinados a entulhos.

Classe B: Podem ser reciclados para outras utilizações, como: papel, papelão, garrafas pets, vidros, metais, madeiras etc. Recomenda-se a separação desses resíduos em caçambas específicas e identificadas para encaminhamento dos mesmos.

Classe C: São aqueles resíduos que não podem ser reciclados e nem recuperados. Devem ser destinados a aterros preparados para o seu recebimento.

Classe D: São aqueles considerados perigosos e capazes de causar danos à saúde humana bem como a sua agressão ao meio ambiente, como: Tintas e solventes. Esses resíduos podem ser encaminhados para áreas de transbordo e triagens (ATTs).

A presente pesquisa surge como uma necessidade de contribuir com as referências bibliográficas que abordam o tema, apresentando uma fundamentação científico-tecnológica, procurando-se investigar, detalhadamente, os fatores que influenciam nas propriedades do concreto utilizado na produção dos blocos.

De acordo com Sousa (2001), esse assunto, na maioria das vezes, é abordado por metodologias, de certa forma, empíricas e não sistêmicas, baseadas em experiências de operários e profissionais da área. As possibilidades de utilização do entulho, como agregado reciclado, em 
substituição aos agregados convencionais, geralmente, empregados na produção dos blocos, também, é analisada.

A pesquisa tem como objetivo avaliar a possibilidade de substituição parcial dos agregados para confecção dos blocos de concreto, por rejeitos da construção civil. Como objetivos específicos, podem-se citar: estudar as propriedades e os parâmetros de mistura dos blocos pré-moldados de concreto; avaliar a influência da granulometria e do consumo de cimento nas propriedades; desenvolver metodologias capazes de orientar a proporcionalidade do traço e avaliar a substituição do agregado por entulho reciclado.

Neste contexto, esta pesquisa estuda a viabilidade de confeccionar blocos de concreto, com a utilização de resíduos da construção civil, utilizando entulho, que atenda às normas técnicas brasileiras vigentes para a execução de blocos, quanto a resistência à compressão, para emprego como material reciclado e para reutilização na construção civil como blocos de vedação.

\section{Materiais e métodos}

Os ensaios desenvolvidos para a pesquisa foram realizados no laboratório de materiais de construção da Pontifícia Universidade Católica de Minas Gerais (PUC Minas), Campus Coração Eucarístico. O laboratório forneceu a maioria dos materiais necessários à execução dos corpos de prova (exceto a fôrma e os rejeitos da construção civil). Foram confeccionados blocos de vedação, utilizando resíduos sólidos da construção civil (entulho), conforme classificação da Resolução 307 do CONAMA (2002), em resíduos de classe A, B e C.

Ao ser elaborado este novo tipo de bloco, executado com rejeitos da construção civil, foi importante avaliar se o mesmo atende as especificações técnicas normativas que são estabelecidas quanto a tolerâncias de dimensão e resistência à compressão do produto. Utilizando-se preceitos da ABNT NBR 6136 (2014), referente a Blocos vazados de concreto simples para alvenaria - requisitos.

O resíduo substituiu o agregado miúdo em cerca de $30 \%$ no traço do concreto convencional. Após o período de sete dias, foi feito a realização de ensaios de esforços à compressão e posteriormente a comparação dos resultados obtidos com o bloco convencional. 


\subsection{Materiais}

\subsubsection{Os rejeitos da construção civil.}

Coletou-se os resíduos sólidos de uma obra situada no Barreiro, Belo Horizonte, Minas Gerais, cujo entulho estava sendo descartado e encaminhado para um aterro através de caçambas estacionadas.

O entulho é constituído de concreto, massa e rebocos de argamassa, que foram selecionados, separados de outros materiais como madeiras, tecidos, plásticos e ferros, placas de gesso, tijolos e blocos cerâmicos, conforme mostrado na Figura 1.

\section{Figura 1 - Rejeitos selecionados}

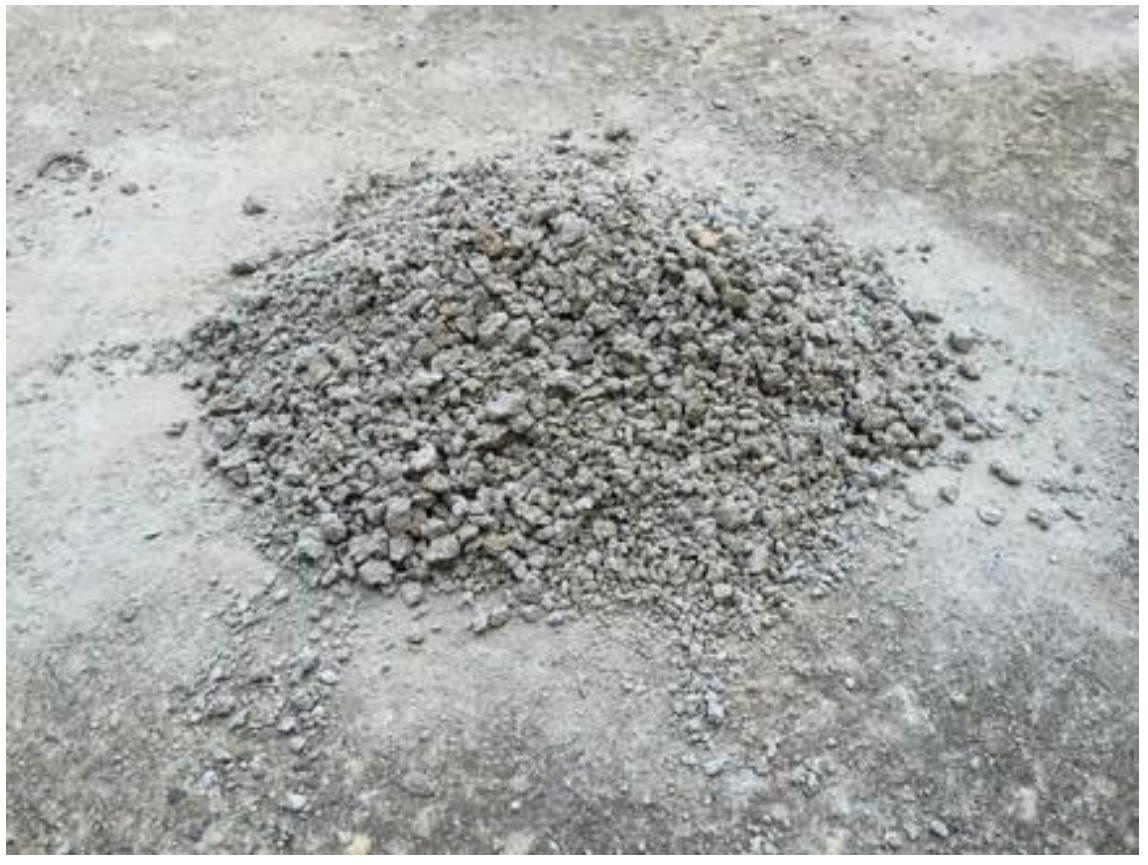

Fonte: Arquivo dos autores, 2017.

Os materiais separados foram triturados e peneirados, conforme mostrado na Figura 2, para que atingissem a granulometria desejada como agregado miúdo, segundo a ABNT NBR 7211 (2005), referente a agregados para concreto e, posteriormente, misturados ao cimento Portland CP V ARI, para que obtivesse a mistura para a confecção de blocos. 


\section{Figura 2 - Rejeitos triturados e peneirados}

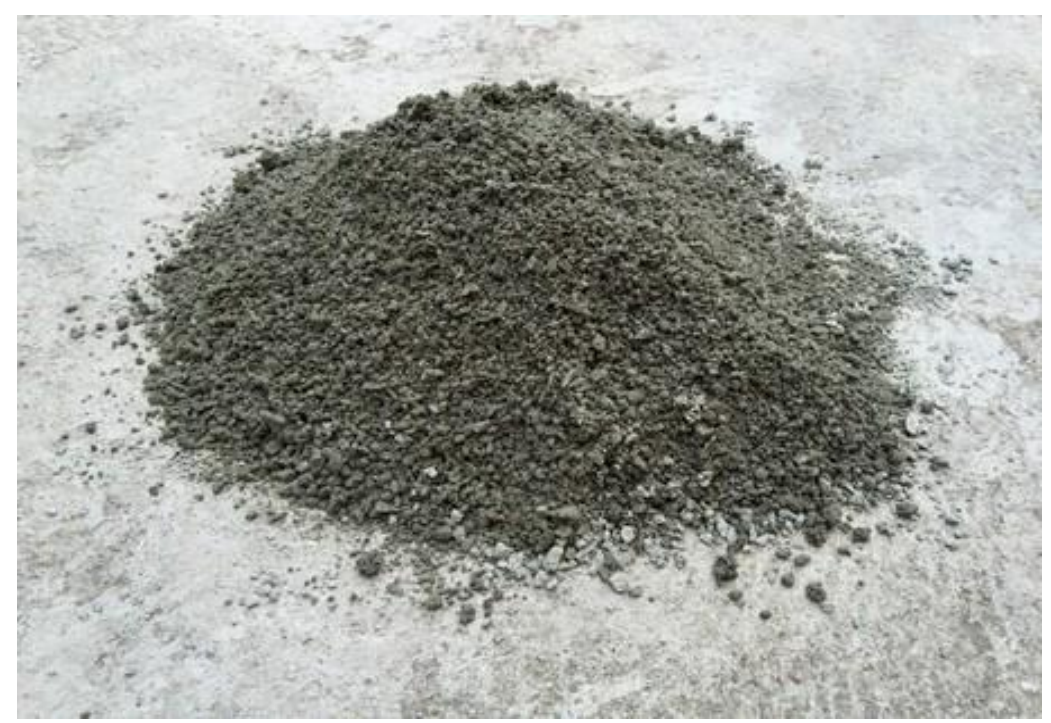

Fonte: Arquivo dos autores, 2017.

\subsubsection{Agregado miúdo e o pó de pedra}

O agregado miúdo utilizado foi disponibilizado pelo laboratório de materiais de construção da Pontifícia Universidade Católica de Minas Gerais (PUC Minas), Campus Coração Eucarístico. Na Figura 3, pode ser visto o agregado miúdo utilizado na confecção dos blocos.

Figura 3 - Agregado miúdo utilizado para confecção dos blocos

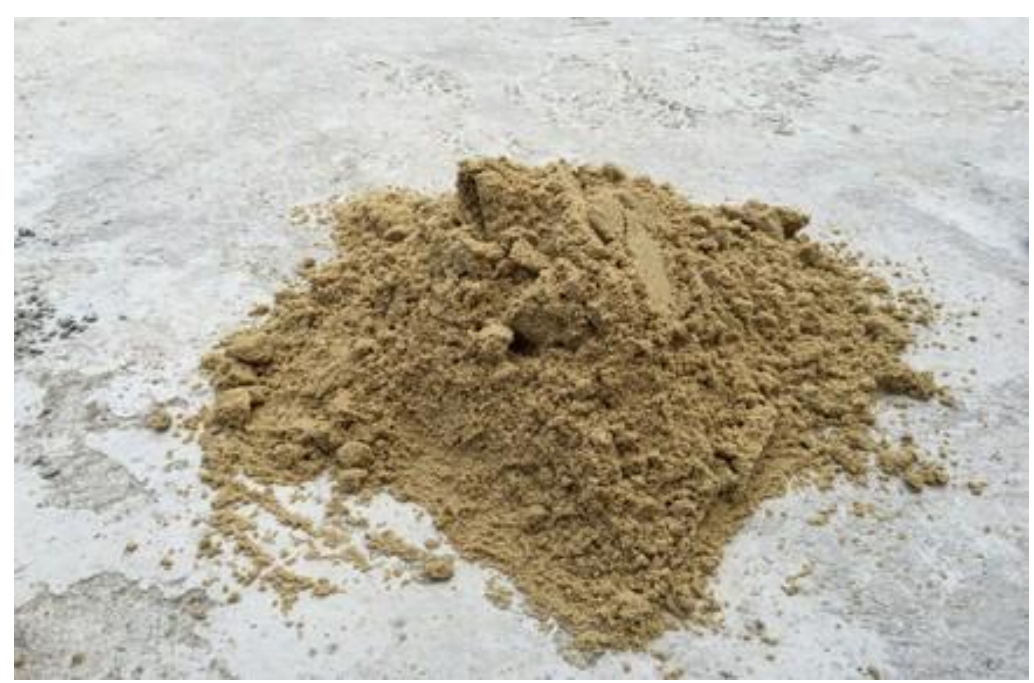

Fonte: Arquivo dos autores, 2017. 
Foi feita a caracterização da massa específica e da dimensão máxima próprio do agregado miúdo, conforme preceitos da ABNT NBR 7211 (2005). Os resultados foram apresentados na Tabela 1.

Tabela1 - Caracterização do agregado miúdo.

\begin{tabular}{|c|c|c|}
\hline Característica & Unidade & Valores \\
\hline Massa Específica & $\mathrm{g} / \mathrm{cm}^{3}$ & 2,584 \\
\hline $\begin{array}{c}\text { Dimensão máxima } \\
\text { característico }\end{array}$ & $\mathrm{Mm}$ & 1,2 \\
\hline
\end{tabular}

Fonte: Arquivo dos autores, 2017.

O pó de pedra foi disponibilizado pela empresa BRASMIC Mineração areia e brita, em Belo Horizonte/MG. Seguindo preceitos da ABNT NBR 7211 (2005).

\subsubsection{Cimento Portland}

Segundo a ABNT NBR 6136 (2004), o cimento empregado deve atender as especificações brasileiras para cimento usando como referência as normas (ABNT NBR 5732, ABNT NBR 5733, ABNT NBR 5735, ABNT NBR 5736, ABNT NBR 5737 e ABNT NBR 11578), destinado à preparação de concretos e argamassas.

O Cimento Portland utilizado foi aquele de alta resistência inicial (CP V - ARI), que atinge altas resistências já nos primeiros dias da aplicação. Este material foi disponibilizado pelo laboratório de materiais de construção da Pontifícia Universidade Católica de Minas Gerais (PUC Minas), Campus Coração Eucarístico, conforme Figura 4. 
Figura 4 - Cimento Portland (CP V - ARI)

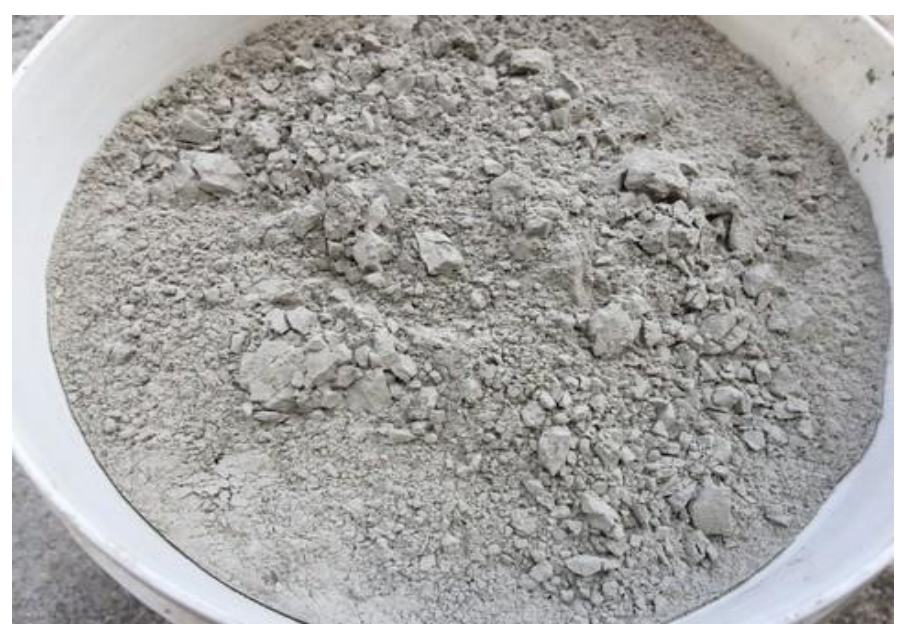

Fonte: Arquivo dos autores, 2017.

\subsection{Métodos}

\subsubsection{Traço utilizado}

Segundo Pini (2000), o traço para a confecção de blocos sem função estrutural é feito por meio de uma dosagem experimental com os materiais disponíveis. Pode-se usar uma areia com qualquer graduação e o fator água/cimento, mantendo-se o traço do concreto constante, deve ser o menor possível.

O traço utilizado para a fabricação de blocos convencionais, sem função estrutural pelos fabricantes, obedece uma proporção de 1:3:3, ou seja, a cada grama de cimento, usa-se 3 vezes a quantidade de cimento em pó de pedra, e 3 vezes a quantidade de cimento em agregado miúdo. A água de amassamento deve atender os critérios da ABNT NBR 15900 (2009), referente a água para amassamento do concreto.

Primeiramente tentou-se usar um traço de 1:1,5:1,5:2, sendo, 1 de cimento, 1,5 de pó de pedra e 1,5 de areia comum e 2 de rejeitos da construção civil, o qual não obteve sucesso na cura deste material, pois não houve agregação dos materiais.

Posteriormente, utilizou-se o seguinte traço: 1:2,5:2,5:1, sendo, 1 de cimento, 2,5 de pó de pedra, 2,5 de areia comum e 1 de rejeitos da construção civil e o resultado foi satisfatório. 


\subsubsection{Moldagem dos corpos de prova}

Os materiais foram misturados de acordo com o traço e, posteriormente, colocados em uma fôrma com dimensões (140 x 190 x 390 mm). De acordo com a ABNT NBR 6136 (2014), o bloco criado foi de designação Classe $\mathrm{D}$, sem função estrutural, para uso em elementos de alvenaria acima do nível do solo. A Figura 5 mostra a mistura dos materiais.

\section{Figura 5 - Mistura dos materiais}

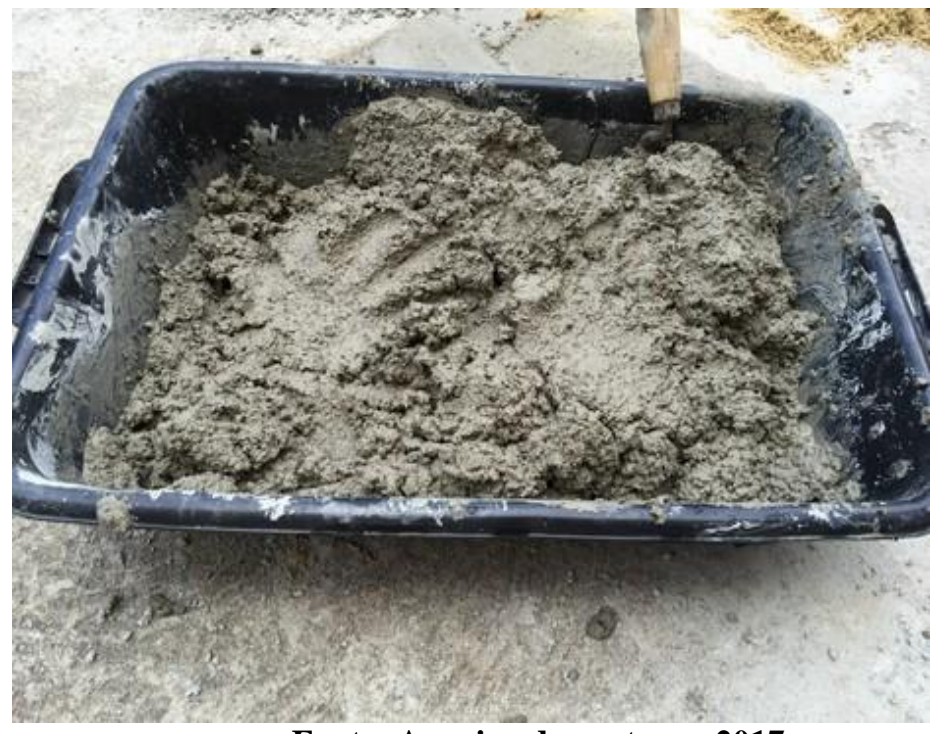

Fonte: Arquivo dos autores, 2017.

Na Figura 6 é mostrado o material misturado na fôrma para confecção do bloco

Figura 6 - Confecção do bloco

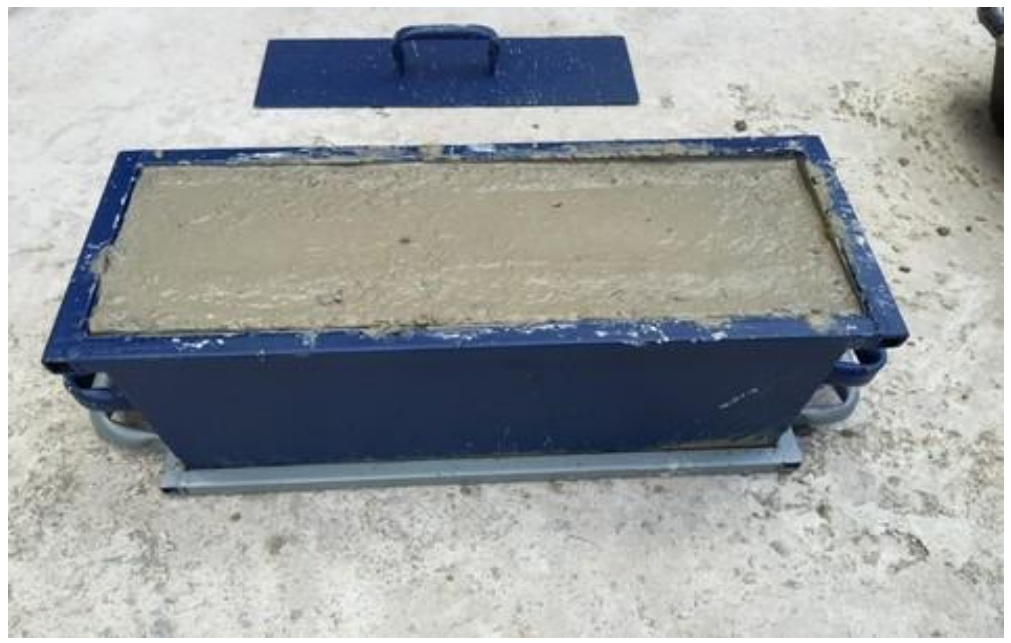

Fonte: Arquivo dos autores, 2017. 
Foram confeccionados 5 corpos de provas, todos com a designação B-14 com dimensões de (140 x 190 x $390 \mathrm{~mm})$, parede transversal e longitudinal com $25 \mathrm{~mm}$ cada, conforme prescreve a ABNT NBR 6136 (2014). A Figura 7 mostra os blocos após serem desformados.

Figura 7 - Blocos de rejeitos confeccionados.

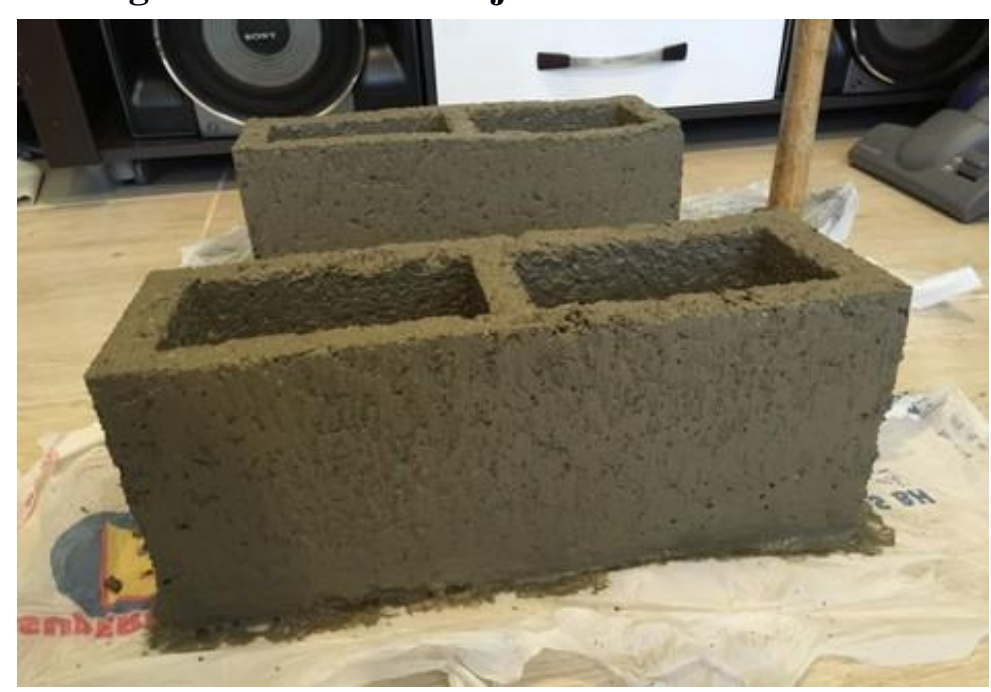

Fonte: Arquivo dos autores, 2017.

\subsubsection{Cura dos corpos de prova}

Segundo a ABNT NBR 6136 (2014), os blocos devem ser curados por processos que assegurem a obtenção de um concreto homogêneo e compacto, de modo a atender todas as exigências. Com base na ABNT NBR 6136 (2014), deixou-se os blocos de concreto, curarem ao ar livre, por 28 dias após a sua confecção, como mostra a figura 8. 


\section{Figura 8 - Blocos após o processo de cura aos 28 dias}

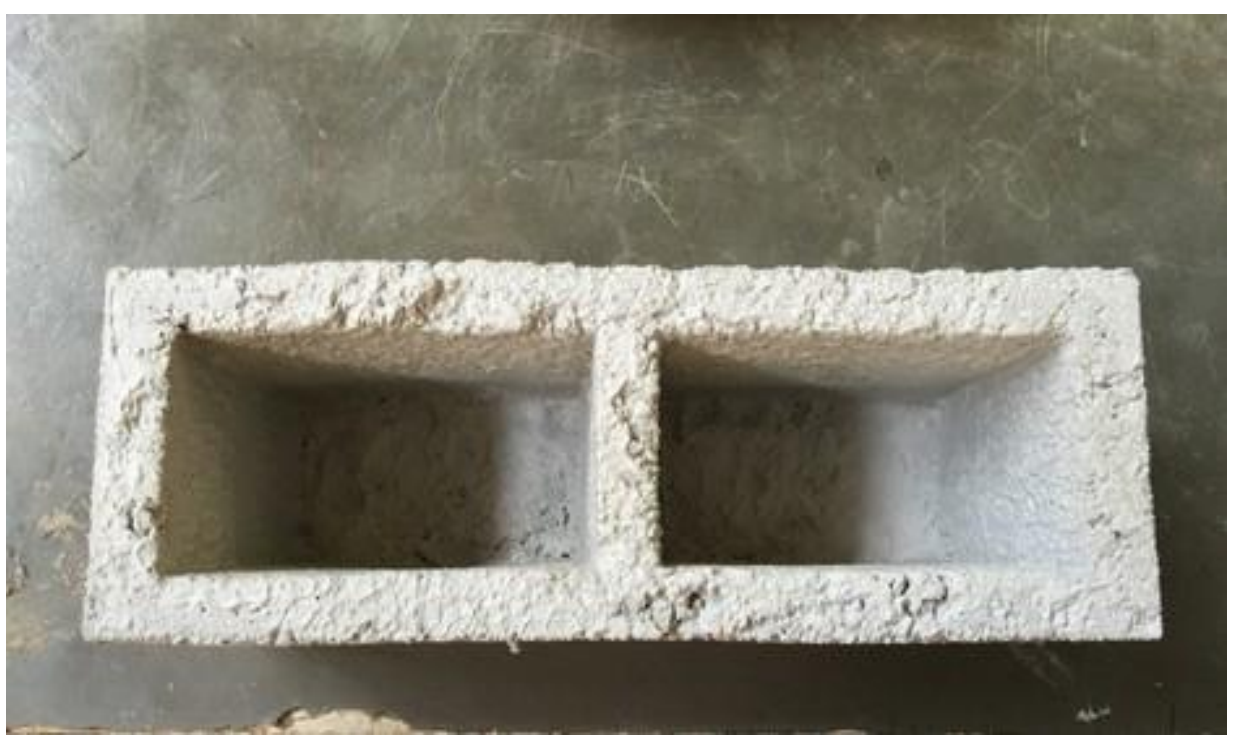

Fonte: Arquivo dos autores, 2017.

\subsubsection{Resistência dos corpos de prova}

Os ensaios de resistência dos corpos de prova foram realizados seguindo a norma ABNT NBR 6136 (2014) de compressão de blocos para vedação. Foram submetidos ao ensaio de resistência à compressão 05 (cinco) exemplares de blocos de concreto com rejeitos da construção civil, com dimensões de (140 x 190 x 390 mm). O ensaio foi realizado na prensa hidráulica da marca Amsler, como mostrada na Figura 9, no laboratório de Materiais de Construção Civil da PUC Minas. 
Figura 9 - Bloco sendo comprimido.

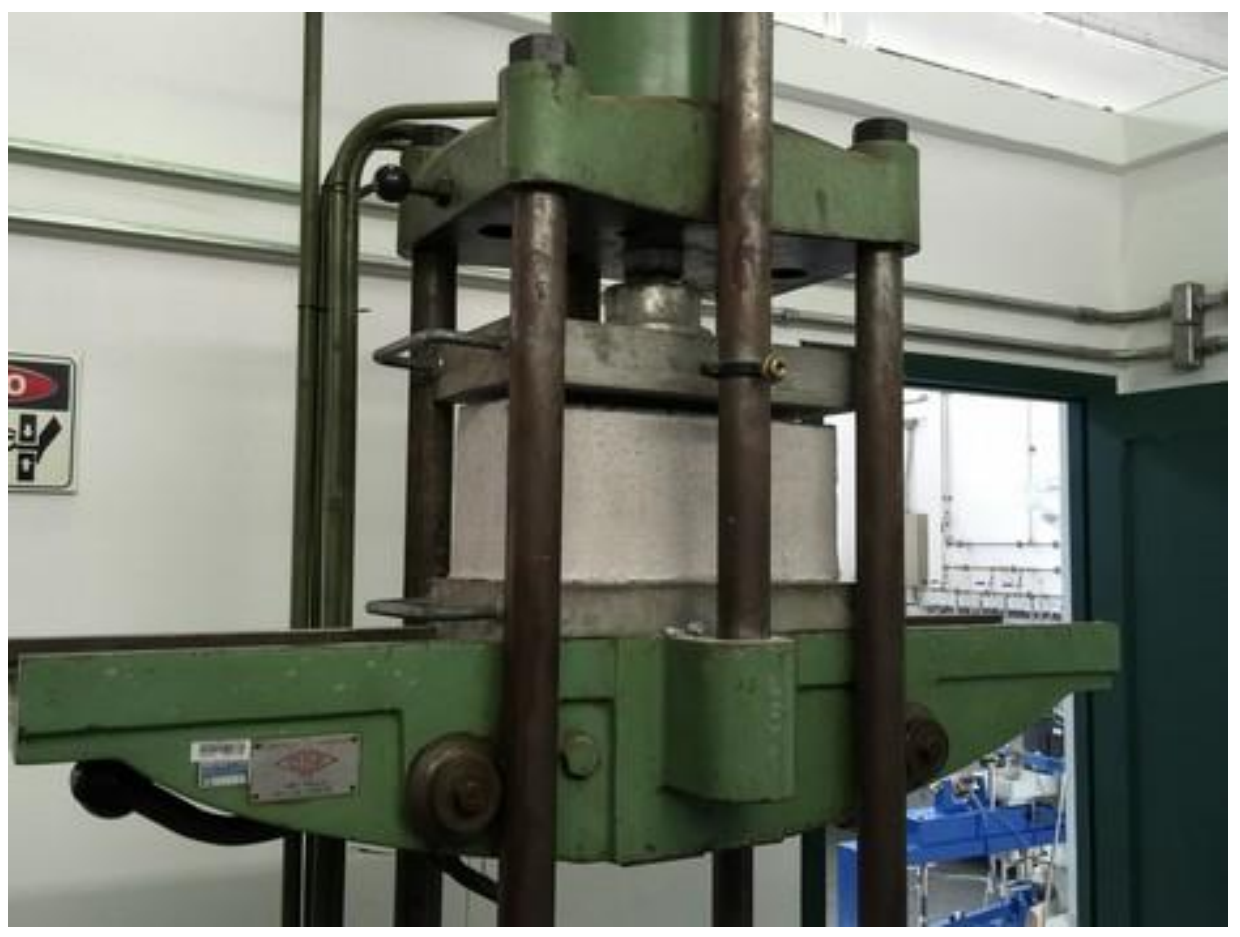

Fonte: Arquivo dos autores, 2017.

A resistência característica, de acordo com a ABNT NBR 6136 (2014), é calculada conforme a equação 1 .

Equação 1 (ABNT NBR 6136,2014):

$$
f b k, \text { est }=2 \frac{f b 1+f b 2+\ldots f b m-1}{m-1}-f b m
$$

Onde:

a) $\quad f b k$,est $=$ Resistência à compressão característica estimada do lote.

b) $\quad f b 1+f b 2+\ldots f b m-1=$ Valores de resistência à compressão dos blocos da amostra, ordenados crescentemente, isto é, $f b 1$ é o menor valor obtido e o $f b m$-1 é o maior.

$\mathrm{O}$ valor de m é obtido de acordo com a equação 2 , se $\mathrm{n}$ for par ou conforme a equação 3 , no caso de $\mathrm{n}$ ser ímpar. Sendo n o número de blocos da amostra.

Equação 2 (ABNT NBR 6136,2014):

$$
m=\frac{n}{2}
$$

Equação 3 (ABNT NBR 6136,2014):

$$
m=\frac{(n+1)}{2}
$$


Os valores das resistências dos corpos de prova, foram colocados em ordem crescente, logo após, somaram-se a resistência do corpo de prova $2(f b 1)$ com a do corpo de prova 5 ( $f b m-1)$. Dividiu-se o resultado por 2 , este que foi obtido por $(m-1)$. Multiplicou-se o resultado por 2 e posteriormente, subtraiu-se pelo valor da resistência do corpo de prova $4(\mathrm{fbm})$.

\section{Resultados e discussões}

De acordo com a ABNT NBR 6136 (2014), os blocos de vedação, classe D, devem possuir resistência característica maior ou igual a $2 \mathrm{MPa}$, conforme indicado na tabela 2.

Tabela 2 - Resistência característica das classes de blocos.

\begin{tabular}{|c|c|c|c|c|}
\hline \multirow{2}{*}{ Classe } & \multirow{2}{*}{$\begin{array}{c}\text { Resistência } \\
\text { caracteristica } \\
f_{b k} \\
M P a\end{array}$} & \multicolumn{2}{|c|}{$\begin{array}{c}\text { Absorção média em } \\
\%\end{array}$} & \multirow{2}{*}{$\begin{array}{c}\text { Retraçâo }{ }^{(1)} \\
\%\end{array}$} \\
\hline & & $\begin{array}{c}\text { Agregado } \\
\text { normal }\end{array}$ & $\begin{array}{l}\text { Agregado } \\
\text { leve }\end{array}$ & \\
\hline A & $\geq 6,0$ & \multirow{4}{*}{$\leq 10,0 \%$} & \multirow{4}{*}{$\begin{array}{c}\leq 13,0 \% \\
\text { (média) } \\
\leq 16,0 \% \\
\text { (individua) }\end{array}$} & \multirow{4}{*}{$\leq 0,065 \%$} \\
\hline B & $\geq 4,0$ & & & \\
\hline C & $\geq 3,0$ & & & \\
\hline D & $\geq 2,0$ & & & \\
\hline
\end{tabular}

Fonte: ABNT NBR 6136, 2014. 
Foram ensaiados 05 (cinco) exemplares de blocos de concreto com rejeitos da construção civil. Os resultados obtidos da resistência à compressão, são mostrados na tabela 3.

Tabela 3 - Teste de compressão das amostras.

\begin{tabular}{|c|c|c|c|c|c|}
\hline Amostra & Largura (mm) & $\begin{array}{c}\text { Altura } \\
(\mathbf{m m})\end{array}$ & $\begin{array}{c}\text { Comprimento } \\
(\mathbf{m m})\end{array}$ & Carga (N) & Resistência(MPa) \\
\hline 1 & 140 & 190 & 390 & 144207 & 2.69 \\
\hline 2 & 140 & 190 & 390 & 109872 & 2.05 \\
\hline 3 & 140 & 190 & 390 & 133416 & 2.49 \\
\hline 4 & 140 & 190 & 390 & 130473 & 2.39 \\
\hline 5 & 140 & 190 & 390 & 125568 & 2,29 \\
\hline & Resistência Característica da amostra (fbk,est) & 1,95 \\
\hline
\end{tabular}

Fonte: Arquivo dos autores, 2017.

A resistência característica da amostra ( $f b k$,est), ficou em 1,95 $\mathrm{MPa}$, inferior a resistência característica prescrita na ABNT NBR 6136 (2014), o qual pede-se que seja igual ou superior a 2 MPa.

Quando em diferentes traços se analisa a proporção cimento/agregado, para uma mesma composição granulométrica (mesma percentagem de agregado), observa-se à influência direta do consumo de cimento na resistência, fato estudado e analisado por Souza (2001). Exemplificando o que foi dito por Souza (2001), ao se reduzir o consumo de cimento (aumentando a proporção cimento/agregado), para a mesma porcentagem de areia se tem uma redução na resistência à compressão. Como era de se esperar, traços com teores maiores de cimento apresentam maiores resistências.

Devido ao fato dos agregados não serem moídos na granulometria correta do agregado miúdo e o traço utilizado não ser compatível, os blocos da amostra não atenderam a resistência necessária, tornando-se inviável a sua utilização em paredes de vedação.

Os resultados das amostras conforme a Figura 10 foram comparados com os exigidos pela norma ABNT NBR 6136 (2014). 
Figura 10 - Comparação entre os resultados.

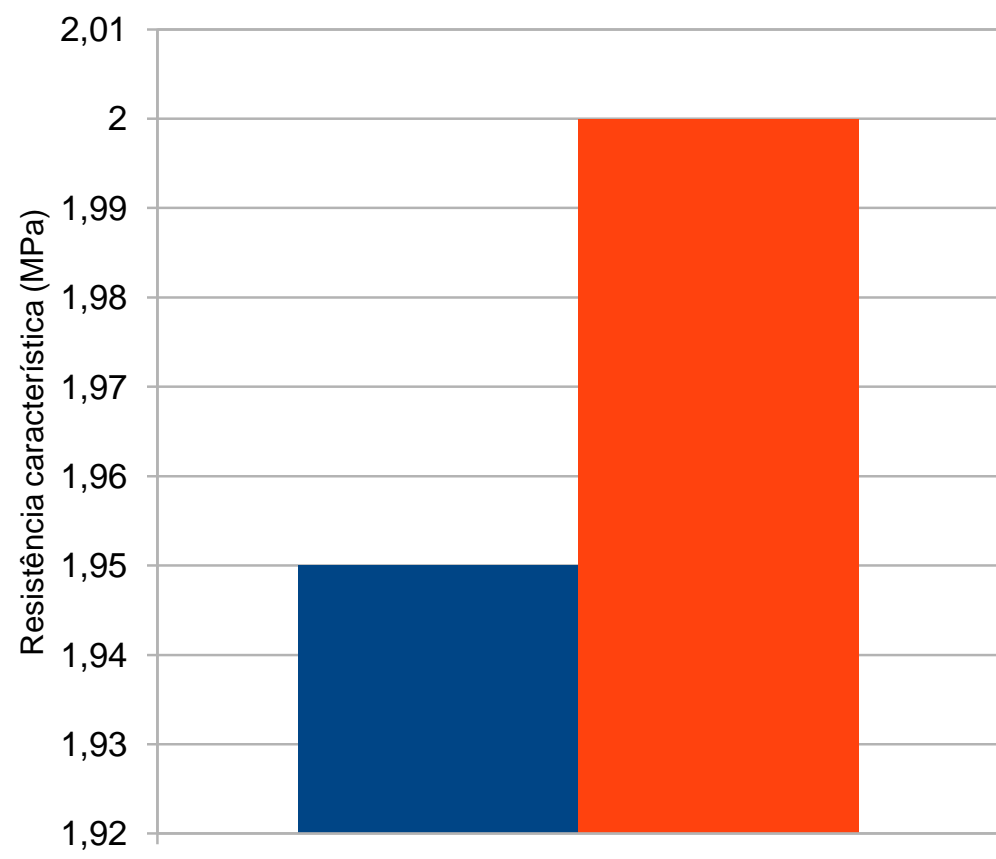

abk,est da amostra

fbk,est ABNT NBR 6136 (2014)

Fonte: Arquivo dos autores, 2017.

\section{Conclusão}

A presente pesquisa buscou encontrar um caminho mais alternativo para a construção civil, propondo mitigar os impactos causados pelos resíduos da construção civil sobre o meio ambiente.

Diante dos resultados experimentais, constatou-se que os blocos feitos com resíduos da construção civil, mostraram-se inviáveis para a utilização como alvenaria de vedação, por não atenderem às condições mínimas de resistência, discretizados na ABNT NBR 6136 (2014).

Para o resíduo reciclado (entulho), utilizado na pesquisa, suas características foram determinantes nas propriedades dos blocos de concreto. É preciso haver um maior controle tecnológico da composição granulométrica do resíduo para a sua empregabilidade como agregado em blocos de vedação. Recomenda-se ainda que outros estudos complementares sejam realizados para avaliar o desempenho desses blocos ao longo do tempo, frente a sua utilização como elemento de vedação. 


\section{REFERÊNCIAS}

ASSOCIAÇÃO BRASILEIRA DE NORMAS TÉCNICAS. ABNT NBR 11578: Cimento Portland Composto. Rio de Janeiro, 1991.

ASSOCIAÇÃO BRASILEIRA DE NORMAS TÉCNICAS. ABNT NBR 5732:1991: Cimento Portland comum. Rio de Janeiro, 1991.

ASSOCIAÇÃO BRASILEIRA DE NORMAS TÉCNICAS. ABNT NBR 5733: Cimento Portland de Alta Resistência Inicial. Rio de Janeiro, 1991.

ASSOCIAÇÃO BRASILEIRA DE NORMAS TÉCNICAS. ABNT NBR 5735: Cimento Portland de alto-forno. Rio de Janeiro, 1991.

ASSOCIAÇÃO BRASILEIRA DE NORMAS TÉCNICAS. ABNT NBR 5736: Cimento Portland Pozolânico. Rio de Janeiro, 1991.

ASSOCIAÇÃO BRASILEIRA DE NORMAS TÉCNICAS. ABNT NBR 5737: Cimento Portland Resistentes a Sulfatos. Rio de Janeiro, 1992.

ASSOCIAÇÃO BRASILEIRA DE NORMAS TÉCNICAS. NBR 7211: Agregado para concreto Especificação. Rio de Janeiro, 2005.

ASSOCIAÇÃO BRASILEIRA DE NORMAS TÉCNICAS. NBR 15900: Água para amassamento do concreto - Parte 2: Coleta de amostras de ensaios. Rio de Janeiro, 2009.

ASSOCIAÇÃO BRASILEIRA DE NORMAS TÉCNICAS. NBR 6136: Bloco vazado de concreto vazado para alvenaria estrutural. Rio de Janeiro, 2014.

BRASIL. Conselho Nacional do Meio Ambiente - CONAMA. Resolução no. 307, de 05 de julho de 2002. Brasília. Diário Oficial da União, de 30 de Agosto de 2002, seção I, p. 17.241.

PINI. Com relação à confecção de blocos vazados de concreto simples, gostaria de saber: 1) Traço ideal (para blocos sem e com função estrutural); 2) Classificação da areia (fina, média, grossa); 3) Fator água/cimento 4) Processo de cura; 5) Alternativa. Revista Pini, 12 de dezembro de 2000. Disponível em: <http://piniweb.pini.com.br/construcao/noticias/com-relacao-aconfeccao-de-blocos-vazados-de-concreto-simples-83709-1.aspx> Acesso em: 04 out. 2017.

SOUSA, J. G. G. Contribuição ao estudo da relação entre propriedades e proporcionamento de blocos de concreto - Aplicação ao uso de entulho como agregado reciclado. 120f. Dissertação de Mestrado, Publicação E.D.M 009A/2001, Departamento de Engenharia Civil e Ambiental, Universidade de Brasília, Brasília, DF, 2001. 